\title{
Psychological Distress Among a Tunisian Community Sample During the COVID-19 Pandemic: Correlations with Religious Coping
}

\author{
Feten Fekih-Romdhane ${ }^{1,2}$ (D) Majda Cheour ${ }^{1,2}$
}

Accepted: 5 March 2021 / Published online: 27 March 2021

(c) The Author(s), under exclusive licence to Springer Science+Business Media, LLC, part of Springer Nature 2021

\begin{abstract}
Despite advances in medicine and technology, when facing epidemics people continue to turn to religion to deal with such unpredictable life-threatening events. We aimed to assess psychological distress in the general population of Tunisia during the COVID-19 pandemic and to examine the contribution of religious coping (RC) in the reports of anxiety and depression at the time of the survey. We carried out and online cross-sectional study using a non-probability snowball sampling technique. A total of 603 responses were recorded. The "Depression Anxiety Stress Scales," the "Brief religious coping scale" and the "Arabic religiosity scale" were used. We found that $28.3 \%, 24.4 \%$ and $19.4 \%$ of the participants reported severe or extremely severe levels of depression, anxiety and stress, respectively. The mean score for positive $\mathrm{RC}$ was $22.8 \pm 5.3$, while that for negative RC was $14 \pm 5.8$. After controlling for confounders, multivariate analysis showed that negative RC significantly and positively contributed to depression and anxiety scores in our respondents, indicating that greater use of negative RC was associated with higher levels of psychological distress. No significant relationship was found between overall religiosity or positive religious coping and either depression or anxiety symptoms. Religious beliefs may have an impact on how people cope with emerging infectious disease outbreaks. Religion should be considered by professionals as an important variable to consider in therapy for individuals who engage in $\mathrm{RC}$ or perceive religious needs.
\end{abstract}

Keywords COVID-19 · Coronavirus · Depression · Anxiety · Psychological distress $\cdot$ Religious coping $\cdot$ Religiosity

Feten Fekih-Romdhane

feten.fekih@gmail.com

Majda Cheour

majda.cheour@yahoo.com

1 Department of Psychiatry "Ibn Omrane”, Razi Hospital, 1 Rue des Orangers, Manouba, Tunisie

2 Faculty of Medicine of Tunis, Tunis El Manar University, Tunis, Tunisia 


\section{Introduction}

The Coronavirus Disease 2019 (COVID-19) epidemic emerged in Wuhan, China (Riou, 2020), spread nationwide and then globally to about 114 countries prompting the World Health Organization (WHO) to declare the COVID-19 a pandemic on March 11, 2020 (WHO, 2020). Along with severe physical health problems, COVID-19 pandemic has generated serious concerns for most societies such as widespread fear and panic (Zhang et al., 2020), as well as feelings of boredom, loneliness and anger among people who are quarantined (Xiang et al., 2020). As a result, and according to similar epidemics and pandemics, the COVID-19 pandemic has led to a wide range of negative psychological reactions on the public, including anxiety and depression (Qiu et al., 2020).

Despite advances in science, medicine and technology, when facing epidemics people react in the same predictable ways as in ancient times, by feeling frightened, anxious and vulnerable, and continue to turn to religion to deal with such unpredictable life events (Tzeng \& Yin, 2006). Ahmadi et al. (2018) argued that religion continues to shape people's response to crisis because religion is more accessible in their sociocultural context than are other resources. Cummings and Pargament (2010) claimed that health-related stressors appear to trigger increases in religious coping (RC). RC may be defined as "the use of religious beliefs or behaviors to facilitate problem-solving to prevent or alleviate the negative emotional consequences of stressful life circumstances" (Koenig et al. 1998, p. 513). A vast empirical literature confirmed that religion has both beneficial and detrimental implications when trying to cope with the challenges and tragedies of life (Pargament, 1997). Indeed, evidence suggested that people use religion to cope in two different ways: "positive" ways of religious coping (e.g., "tried to put my plans into action together with God") that record a sense of meaningfulness and of connection with God and predict more successful coping, and "negative" ways ("Wondered what I did for God to punish me") that reflect an insecure relationship with God and a struggle to find religious meaning in life and thus tend to be associated with more problematic outcomes (Pargament et al., 1998; Pargament et al. 2011, p. 57).

There has been very limited published literature regarding spiritual and religious needs in people who face an unknown disease (Tzeng \& Yin, 2006), although more recently there has been an emerging collection of literature with regard to COVID-19 (e.g., Hart \& Koenig, 2020; Carey, Swift \& Burton, 2020; Carey, 2020). In previous experiences with serious infectious disease outbreaks, some studies highlighted that nonclinical and clinical individuals tried to obtain available support and resources through religion. For example, during the SARS outbreak religion represented one of the coping strategies that helped healthcare workers to reduce their psychiatric symptoms despite their medical knowledge and training about the disease (Chan \& Huak, 2004; Sim et al., 2004). Knowing that there was no cure for SARS, a 26-year-old Taiwanese SARS infected medical doctor reported in his diary having relied on a religious power to cure his SARS, and having asked his relatives, friends, teachers and colleagues to pray 
for him (Wu, 2004; cited in: Tzeng \& Yin, 2006). A study carried out in Uganda among adult Ebola survivors and their family caregivers found that, to avoid the trauma of Ebola and to overcome unpleasant feelings related to its constant threat, respondents mostly used prayer as a coping response (Matua \& Van der Wal, 2015). In a qualitative study that aimed to examine the ways in which New England residents appraised the threat of H1N1 and coped with H1N1-related stressors, participants claimed that "a higher power" (God) helped them to face challenges encountered during $\mathrm{H} 1 \mathrm{~N} 1$ and to reduce the emotional impact of the flu pandemic. Participants reported using "a special protection over them that comes from [God] the Father" to cope with public health emergencies and that to be prepared, they "love God and then call 911." In light of these statements, the authors suggested that "pandemic planners should direct more effort to supporting the religious and community organizations that can help local residents cultivate this resilient quality" (McCauley et al., 2013).

Prior research found that, when confronted with a stressor, Muslims use religion as a coping strategy at higher rates in comparison with other religious groups (Bhui et al., 2008; Cinnirella \& Loewenthal, 1999). However, considerable controversy exists regarding the effects of religious coping among Muslim populations, with religion being a source of both strength and vulnerability in various samples (Adam \& Ward, 2016).

Tunisia confirmed its first COVID-19 case on March 2, 2020. In Tunisia as in the entire Muslim world, mosques suspended Friday and daily congregational prayers in effort to prevent further uncontrolled spread of the virus. Stopping Friday prayer, which is the only prayer that has to be performed in a mosque for every adult male Muslim, has never occurred since its introduction by Prophet Muhammad in 622 (Ozalp, 2020). Instead, mosques and Tunisian local TV stations broadcasted daily Islamic supplication asking God's intervention to stop the spread of COVID19. Moreover, Saudi Arabia closed the Great Mosque of Mecca and decided for the first time to cancel the annual and main pilgrimage to Mecca for 2020 due to the pandemic. All these changes were challenging for Muslim communities and have led some Muslims to believe that God created the COVID-19 pandemic to warn and punish humanity for several misdeeds (Ozalp, 2020). Such thinking may differentially impact mental health outcomes. Our objectives were to assess psychological distress in the general population of Tunisia during the time of the COVID-19 pandemic and to examine the contribution of religious coping in the reports of anxiety and depression at the time of the survey.

\section{Methods}

\section{Procedure}

An online cross-sectional study, related to the psychological distress in the community during the COVID-19 pandemic, was conducted using a non-probability snowball sampling technique. As the Tunisian Government recommended the public to isolate themselves at home and imposed a general lockdown at the time of the 
survey, potential respondents were electronically invited by existing study respondents. The data collection was initiated on April 9, 2020, and closed on April 15, 2020. During this period, Tunisia was going through a phase of increase in the number of newly diagnosed COVID-19 cases and related deaths.

An online semi-structured questionnaire was developed by using google forms, with a consent form appended to it. On receiving and clicking the link, participants were auto-directed to the information about the study and informed consent. After they accepted to take the survey, a set of several questions appeared sequentially, which the participants were to answer. All the participants had to be above 18 years of age, Tunisian origin living currently in Tunisia, Muslim, and had to have access to the Internet and a sufficient knowledge of the literary Arabic language. A total of 603 responses were recorded.

\section{Sample Characteristics and Assessments}

The online self-reported questionnaire contained three sections. The first section contained questions about sociodemographic variables, including age, gender, marital status, current living arrangement, residency, personal history of psychiatric and somatic diseases. Another section of the questionnaire included COVID-19-related variables. Exposure was assessed in three ways. We assessed direct exposure, media exposure and resource deprivation as a result of the COVID-19. In the current study, four items were used to assess direct COVID-19 exposure, including being (or having been) personally affected by the COVID-19, discussing with another person the details of a person's illness or death due to COVID-19, having someone close who was a confirmed case or who died of COVID-19. Resource deprivation was assessed using five dichotomous questions that measured experiences of lacking necessities such as food, medical care, personal supplies, communicating with loved ones. Media exposure was measured by a one item. All participants were asked to estimate the average number of hours per day they spent watching the news about the COVID-19 via media platforms (e.g., newspaper, radio, television, Internet, social media networks, etc.) in the month before the survey. A third section contained four research instruments:

\section{The Depression Anxiety Stress Scales (DASS-21)}

The DASS-21 (Lovibond \& Lovibond, 1995) is a self-administered scale composed of 21 items of self-assessment under three scales: depression, anxiety and stress. The subject indicates to what extent each item corresponds to it, on a scale of Likert ranging from 0 (no symptoms) to 3 (symptom present intensively). The following cutoff scores have been used for defining mild/moderate/severe/extremely severe scores for each DASS scale: depression: normal (0-4), mild (5-6), moderate (7-10), severe (11-13), extremely severe (14+); anxiety: normal (0-3), mild (4-5), moderate (6-7), severe (8-9), extremely severe $(10+)$; stress: normal (0-7), mild (8-9), moderate (10-12), severe (13-16), extremely severe $(17+)$. Previous studies showed 
a good internal consistency of the validated Arabic version of the DASS-21 used in our study (Moussa et al., 2017).

\section{Arabic Brief religious Coping Scale, A-BRCS}

The Brief religious coping scale of Pargament is an instrument of 14 items measuring the different aspects of religious coping strategies (Pargament et al., 2000). It is composed of two parts: positive religious coping (PRC) and negative religious coping (NRC). The PRC subscale assesses efforts to maintain a secure relationship with God, believing that there is a positive meaning to be found in the stressor, and let go of negative emotions. The NRC subscale assesses perceptions of a disrupted or conflictual relationship with God, a belief that the devil caused the stressor, as well as a religious struggle in the search for the meaning of life. These are two subscales of Likert in four points, ranging from 1 (strongly disagree) to 4 (strongly agree), with a total score ranging from 7 (low) to 28 (high). Arabic Brief religious coping scale (A-BRCS) used in this study produced the following Cronbach's alpha coefficients: positive subscale $=0.86$, negative subscale $=0.82$ (Al-Hadethe et al., 2016).

\section{Arabic Religiosity Scale, ARS:}

The ARS was designed by Khalaf et al. (2014) to measure participants': (a) behavioral religiosity, public and private (first two questions), (b) cognitive/affective importance of religiosity in the total curriculum of one's life and at time of difficulties (third and fourth questions) and (c) general self-rate level of belief (last question). The participants must answer five questions about religiosity on a four-point Likert response scale, ranging from 0 (never, not important, absent) to 3 (always, major, most of the time, strong). Final scores are defined as follows: (0-5) low level of religiosity, (6-10) moderate level of religiosity, (11-15) high level of religiosity. The first two items measure behavioral religiosity, public and private. The third and the fourth items measure affective religiosity, and the last question measures the general level of faith. The scale has a high test-retest reliability $(\mathrm{k}=0,77)$, as well as a high internal consistency $(\alpha=0,8)$ (Khalaf et al., 2014).

\section{Multidimensional Scale of Perceived Social Support (MSPSS)}

The MSPSS is a brief and widely used self-report tool for the assessment of social support (Zimet et al. 1988). It provides assessment of three sources of perceived social support: family, friends and significant other. Each item is rated on a 7-point Likert rating scale ( $1=$ very strongly disagree, $7=$ very strongly agree), higher scores indicating higher perceived social support. The MSPSS appears to be a psychometrically reliable and valid instrument for use across clinical and non-clinical population. An Arabic version of the MSPSS (Merhi \& Kazarian, 2012) was used in this study, which had excellent internal consistency $(\alpha=0.87)$ and reliability. 


\section{Statistical Analysis}

Data were analyzed using SPSS, ver. 18. Distribution of continuous variables was compared to normal distribution via Shapiro-Wilks test. Data were expressed as a frequency for the nominal variables and as mean \pm standard deviation (SD) for the continuous variables. Bivariate correlations among all variables were investigated using Pearson product-moment correlation coefficients. We carried out t test and one-way ANOVA to determine the univariate links between distress scores and socio-demographic data, and COVID-19-related variables.

Hierarchical multiple regression analysis was carried out to isolate predictors which have significant influence on depression and anxiety. We thus constructed two models with the depression and anxiety total scores as dependent variables. The independent variables were divided into four blocks: a first block containing demographic variables (age and gender), a second block containing psychosocial variables (personal psychiatric history and perceived social support), a third block including COVID-19-related variables (exposure, daily time spent on media and resource deprivation) and a fourth block including religious variables (overall religiosity and religious coping). In all statistical tests, the significance threshold was set at 0.05.

\section{Results}

The sample had a male/female sex ratio of 0.35 . The other characteristics of the study sample are summarized in Table 1. The DASS scores revealed that $28.3 \%$, $24.4 \%$ and $19.4 \%$ of the participants reported severe or extremely severe levels of depression, anxiety and stress, respectively. For a threshold value of 10, 83.4\% of the participants $(n=503)$ had a high level of religiosity. The mean score for positive religious coping was $22.8(\mathrm{SD}=5.3)$, while that for negative religious coping was $14.4(\mathrm{SD}=5.8)$.

Pearson correlations (matrix found in Table 2) indicated that NRC significantly and positively correlated with depression, anxiety and stress scores $(p<0.001)$ in our participants. PRC and overall religiosity level negatively correlated with depression and stress scores. Age and perceived social support negatively correlated with depression, anxiety and stress scores.

Table 3 shows results from the hierarchical multivariate regression analysis. We entered demographic variables into the model at step 1. Age and gender contributed significantly to participants' depression and anxiety. Demographic variables accounted for $9.2 \%$ of the variance in depression scores and $6.2 \%$ in anxiety scores. In step 2, we added personal psychiatric history and perceived social support. Psychiatric history represented significant contributor to distress. They accounted for $8 \%$ of the variance in depression scores and for $7.8 \%$ in anxiety scores. COVID19 -related variables (exposure, daily time spent on media and resource deprivation) were added in step 3. These variables combined explained $8.6 \%$ of the variance in depression and $6.8 \%$ of the variance in anxiety. After including religious covariates (religiosity and religious coping) in the final step, only the NRC made a significant contribution to the prediction of depression, increasing the total variance 
Table 1 The Tunisian Muslim community participants' characteristics $(N=603)$ during the COVID-19 pandemic

\begin{tabular}{|c|c|}
\hline & $N(\%)$ \\
\hline \multicolumn{2}{|l|}{ Gender } \\
\hline Male & $157(26.0 \%)$ \\
\hline Female & $446(74.0 \%)$ \\
\hline \multicolumn{2}{|l|}{ Marital status } \\
\hline Single & $430(71.3 \%)$ \\
\hline Married & $161(26.7 \%)$ \\
\hline Divorced/Separated & $10(1.7 \%)$ \\
\hline Widower & $2(0.3 \%)$ \\
\hline \multicolumn{2}{|l|}{ Living arrangement } \\
\hline With parents & $384(63.7 \%)$ \\
\hline With spouse & $138(22.9 \%)$ \\
\hline With parents and spouse & $15(2.5 \%)$ \\
\hline With friends & $29(4.8 \%)$ \\
\hline Alone & $37(6.1 \%)$ \\
\hline \multicolumn{2}{|l|}{ Residency } \\
\hline Urban area & $562(93.2 \%)$ \\
\hline Rural area & $41(6.8 \%)$ \\
\hline \multicolumn{2}{|l|}{ Personal psychiatric history } \\
\hline Yes & $72(11.9 \%)$ \\
\hline No & $531(88.1 \%)$ \\
\hline \multicolumn{2}{|l|}{ Personal history of somatic diseases } \\
\hline Yes & $36(6.0 \%)$ \\
\hline No & $567(94.0 \%)$ \\
\hline \multicolumn{2}{|l|}{ COVID-19 exposure } \\
\hline $\begin{array}{l}\text { Hearing or discussing with another person the details of a person's illness or death due to } \\
\text { COVID-19 }\end{array}$ & $167(27.7 \%)$ \\
\hline Someone close being a confirmed case of COVID-19 & $34(5.6 \%)$ \\
\hline Someone close being died of COVID-19 & $15(2.5 \%)$ \\
\hline Being (or having been) personally affected by the COVID-19 & $1(0.2 \%)$ \\
\hline None of these experiences & $410(68.0 \%)$ \\
\hline \multicolumn{2}{|l|}{ Total time spent on news and events related to COVID-19 on media ${ }^{*}$ per day } \\
\hline$<1 \mathrm{~h}$ & $198(32.8 \%)$ \\
\hline $1-2 \mathrm{~h}$ & $195(32.3 \%)$ \\
\hline $3-4 \mathrm{~h}$ & $110(18.2 \%)$ \\
\hline$>5 \mathrm{~h}$ & $100(16.6 \%)$ \\
\hline \multicolumn{2}{|l|}{ Resource deprivation } \\
\hline Not able to communicate with loved ones & $356(59.0)$ \\
\hline No access to needed healthcare (for conditions other than COVID-19) & $65(10.8)$ \\
\hline No access to food & $55(9.1)$ \\
\hline Difficulty obtaining personal supplies (e.g., medication) & $49(8.1)$ \\
\hline Financial problems and/or risk of job loss & $124(20.6)$ \\
\hline None of these & $168(27.9)$ \\
\hline
\end{tabular}

*Television, radio, press, social networks, other websites

SD Standard deviation 
explained by the model to $28.2 \%$, an addition $2.5 \%$ of total variance in depression (R2 change $=0.025, p<0.001)$. Moreover, NRC positively predicted anxiety and accounted for $1.5 \%$ of the variance in anxiety scores.

\section{Discussion}

To the best of our knowledge, this study is the first community survey of the relationship between psychological distress and religious coping with a newly emerging infectious disease. Our results were consistent with literature data reporting relatively high depression, anxiety and stress scores in the general population during the time of the COVID-19 pandemic. A longitudinal study that surveyed the Chinese general population ( $n=1738$ respondents) found moderate to-severe stress, anxiety and depression during the initial outbreak in $8.1 \%, 28.8 \%$ and $16.5 \%$ of the respondents, respectively (Wang et al., 2020). A nationwide large-scale survey in the general population of China ( $n=52,730,64.73 \%$ females) during the COVID-19 epidemic found that almost $35 \%$ of the respondents experienced psychological distress (Qiu et al., 2020).

The majority of participants $(83.4 \%)$ had a high level of religiosity. This testified to the importance that the religion occupies in the lives of the Tunisian people, which is in agreement with literature. Indeed, religiosity is an important entity in the life of most Arab Muslim-majority populations (Hood et al., 2003). Bivariate analyses showed that overall religiosity correlated negatively with distress, indicating that religion played a protective role in our participants. However, in the multivariate analysis, and after adjusting for study variables, only NRC made a unique statistical contribution to the model.

Most recent literature supported that there is a beneficial relationship between religiousness and many mental health indicators, including anxiety and depressive symptoms in both healthy and clinical populations (e.g., Lawler-Row \& Elliott, 2009; Shreve-Neiger \& Edelstein, 2004). Religion is thought to be associated with a healthier personality, that is, able to manage life crises (Gearing \& Lizardi, 2009). In line with these findings, several studies in Muslim-Arab countries including Kuwait, Lebanon, Palestine, Qatar, Saudi Arabia, Egypt, Algeria, and Tunisia have advocated for the protective role of religion towards anxiety, depression, hopelessness and suicidal ideations and behaviors (Abdel-Khalek, 2014; Fekih-Romdhane et al., 2020).

We found that our respondents have used more PRC than NRC to cope with COVID-19. After controlling for the effects of potential confounding variables, multivariate analysis showed that NRC significantly and positively contributed to depression and anxiety scores in our respondents, indicating that greater use of NRC was associated with higher levels of psychological distress. Our findings were consistent with prior research that has demonstrated the harmful effects of NRC (Ano \& Vasconcelles, 2005). Indeed, religious coping has different facets and seems to be an ambivalent phenomenon that may lead to beneficial or detrimental outcomes. Reliance on God's help may provide a sense of global meaning in life in patients as well 


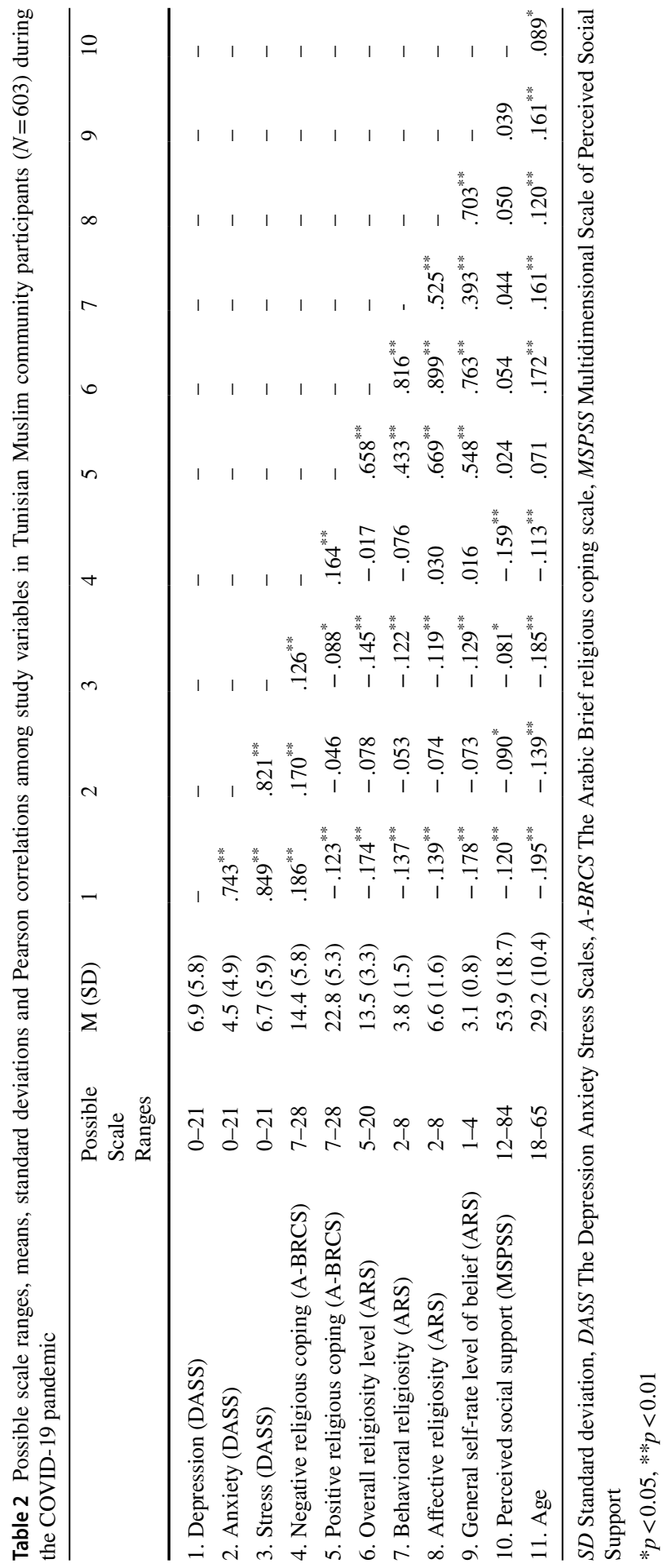




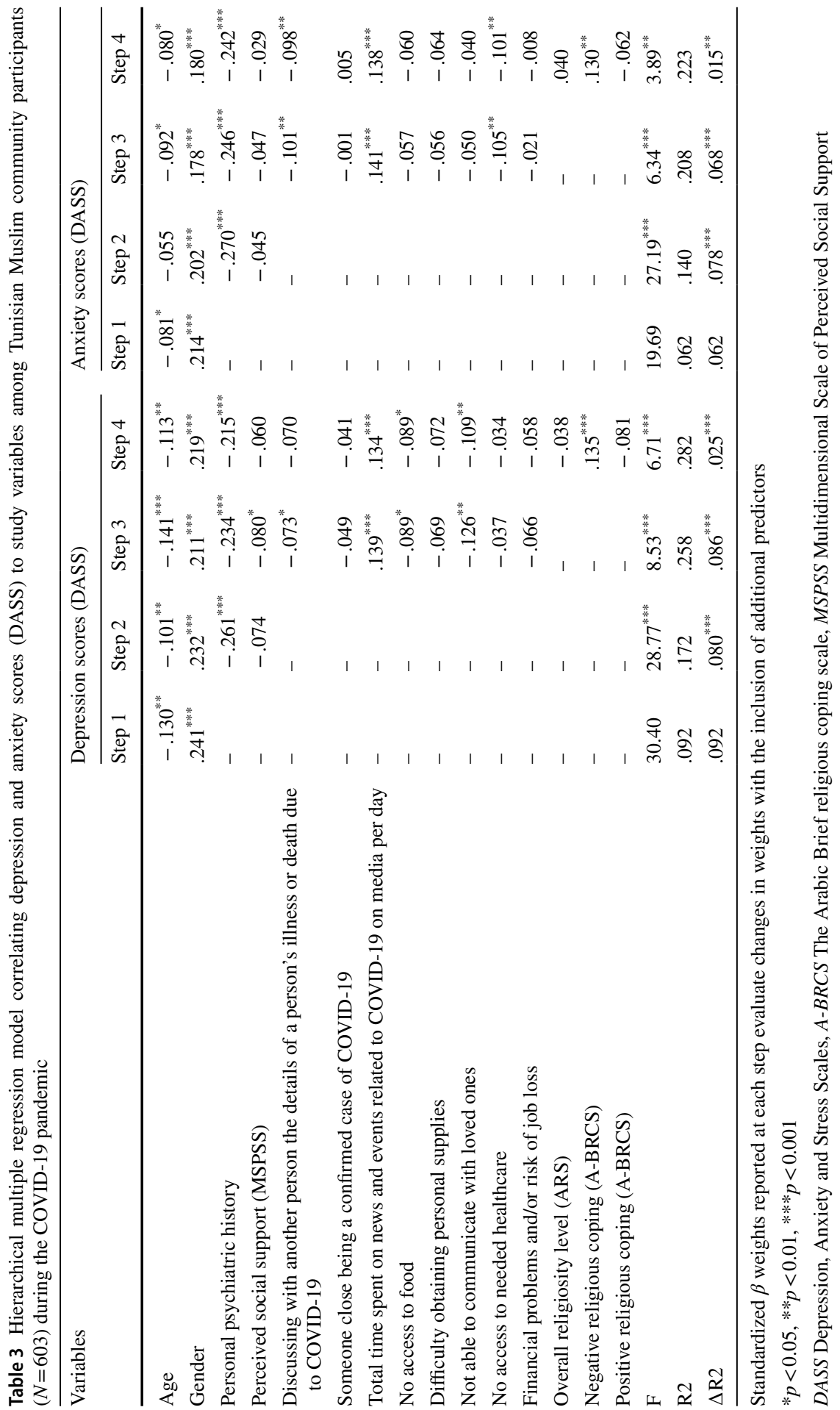


as healthy individuals, and help subjects believe in a meaningful reason for contracting a disease (Ironson \& Kremer, 2009), perceive certain positive consequences of their illness (Karademas, 2010) and view illness as a 'chance' (Büssing et al., 2009). According to Büssing et al. (2009), religious coping would be a vital "preexisting" resource to cope (prior to the onset of the disease), which is utilized to deal with life concerns when confronted with an existential need. However, in some cases, people may view medical conditions as an indication of being abandoned or punished by God and might thus experience distressing doubts about their faith (Cummings \& Pargament, 2010). Research to date has shown strong support for adverse relations between negative religious coping and mental health. Religious struggles resulting from NRC, and defined as "expressions of conflict, question and doubt regarding matters of faith, God and religious relationships" (McConnell et al., 2006, p. 1470), have been related to outcomes such as depression, anxiety, difficulty adjusting to traumatic life events (Wilt et al., 2016). Ano and Vasconcelles (2005) meta-analyzed 49 relevant studies examining the relationship between religious coping and psychological adjustment to stress, and found that individuals who reported using negative forms of religious coping experienced more psychological adjustment to stress (e.g., more depression, anxiety and distress). The authors explained these results by the fact that NRC "represents a burden for people undergoing stressful situations." However, it is worth highlighting that a causal direction of the association between NRC and distress cannot be established in our study. A bidirectional relationship between these two constructs is quite possible. Thus, the psychological distress caused by the pandemic crisis may have precipitated the increased use of negative religious coping among our population, and this religious struggle may have been exacerbated by the preexisting distress (Ellison \& Lee, 2010). Moreover, since bivariate analyses objectified that religion played a protective role in managing the psychological consequences of the COVID-19 pandemic, effects of the positive religious coping may have been concealed by distress in multivariate analysis. Indeed, participants in distress would have turned to religion to cope with the pandemic, creating an artificial positive relationship between religiosity and distress, which negates the inverse relationship found in bivariate cross-sectional correlations.

We believe that these data as well as our findings add support to the usefulness of better knowing religious beliefs and even integrating Islamic beliefs and practices in the psychotherapeutic process of Muslims to cope with psychological distress in times of crisis (Fekih-Romdhane et al., 2020). Tzeng and Yin (2006) claimed that learning about health care related cultural and religious beliefs and respecting individual religious needs related to their cultural or religious orientations when facing an unknown infectious disease may contribute to offering ethical care. In line with the concept of religion as a resource in managing stressful situations and distress, Marshall and Smith (2015) made recommendations to engage religious actors to strengthen future infectious disease outbreak responses. Authors claimed that during the Ebola epidemic, "national governments and international actors were late to appreciate the vital roles of religious actors in addressing Ebola and supporting health systems." Taking account of the presence of religious institutions would strengthen both health service delivery and public health approaches. Several measures that are crucial in public health approaches to infectious disease (e.g., health 
messages, guarantee of proper quarantine procedures) would be facilitated by religious communities' involvement (Marshall \& Smith, 2015).

This study has several strengths. First, its sample size was adequate. Second, we used well-validated questionnaires to examine psychological distress, religiosity and religious coping. Third, multiple variables including demographics, social support, personal psychiatric history, COVID-19-related variables and religiosity were statistically controlled when examining the associations between depression, anxiety and religious coping. Fourth, clinical research in the effect of religion on COVID19-related psychological distress is still lacking.

Despite the strengths of the study, these findings need to be interpreted with considering the following limitations. First, all data were assessed by self-report, which may have led to biased reporting of depression, anxiety, perceived social support, religiosity and religious coping. Second, causal inferences between religious coping and psychological distress cannot be derived from the current study because of its cross-sectional design. Future studies using longitudinal designs could help to clarify the temporal linkages between religious coping and mental health outcomes of the COVID-19 pandemic. Third, given the context of the COVID-19 outbreak in which sampling represent a major issue, we were forced to adopt the snowball sampling strategy. Thus, our study sample may not reflect the actual pattern of the general population. This sampling method was used in many previous studies in the context of the COVID-19 (e.g., Liu et al., 2020; Roy et al., 2020; Wang et al., 2020).

\section{Conclusion}

Religious beliefs may have an impact on how people cope with newly emerging infectious disease outbreaks. In considering our findings, religious coping must not be dismissed by professionals as it may work in conjunction with medical treatment to promote health (Cummings \& Pargament, 2010). To respond sensitively to individuals' religious needs, clinicians need to learn about health care related religious beliefs and activities in their communities and to acknowledge that these may be very different from their own beliefs (Tzeng \& Yin, 2006). Cummings and Pargament (2010) recommended to begin by determining whether the individual engages in religious coping or perceives religious needs, and in case it is relevant for them, to encourage use of positive religious coping techniques rather than negative ones.

Also, mental health research should recognize religion as an important variable to consider in therapy when working with Muslim clients (Pargament, 1997, 2011). A previous literature review on Muslim mental health has highlighted the importance of religiously integrated psychotherapy (Abu Raiya \& Pargament, 2010). Post and Wade (2009) suggested that religious interventions play an effective role to help religiously oriented subjects, including typical psychotherapy techniques that are integrated with a religious perspective (e.g., integrating Islamic values within cognitive behavioral therapy), prayer and teaching religious concepts.

On a larger scale, during life-threatening pandemics such as COVID-19, healthcare systems and religious institutions should work together to transmit accurate 
messages that address people's concerns about COVID-19 challenges and to mitigate harmful misinformation. For example, Bah and Aljoudi (2014) described some beneficial Islamic teachings that are particularly relevant to epidemics, such as the fact that it is permissible not to wash bodies of deceased relatives if washing them would expose washers to harm. Moreover, Marshall (2016) cited a previous example of religious communities roles in combatting the epidemics, namely "the Religious Leaders' Ebola Response Task Force that focused on framing and disseminating media messages on prevention and how to respond when cases were suspected."

Funding All authors declare that they received no source of funding for this study.

\section{Declarations}

Conflicts of interest The authors declare that they have no conflict of interest.

\section{References}

Abdel-Khalek, A. M. (2014). Religiosity and well-being in a muslim context. In C. Kim-Prieto (Ed.), Religion and spirituality across cultures, cross-cultural advancements in positive psychology.

Abu Raiya, H., \& Pargament, K. I. (2010). Religiously integrated psychotherapy with Muslim clients: From research to practice. Professional Psychology: Research and Practice, 41(2), 181-188. https:// doi.org/10.1037/a0017988

Adam, Z., \& Ward, C. (2016). Stress, religious coping and wellbeing in acculturating Muslims. Journal of Muslim Mental Health, 10(2), 3-26. https://doi.org/10.3998/jmmh.10381607.0010.201

Ahmadi, F., Khodayarifard, M., Zandi, S., Khorrami-Markani, A., Ghobari-Bonab, B., Sabzevari, M., \& Ahmadi, N. (2018). Religion, culture and illness: A sociological study on religious coping in Iran. Mental Health, Religion and Culture, 21(7), 721-736. https://doi.org/10.1080/13674676.2018. 1555699

Al-Hadethe, A., Hunt, N., Thomas, S., \& Al-Qaysi, A. (2016). Cross-cultural validation and psychometric properties of the Arabic brief religious coping scale (A-BRCS). Journal of religion and health, 55(1), 16-25. https://doi.org/10.1007/s10943-014-9963-7

Ano, G. G., \& Vasconcelles, E. B. (2005). Religious coping and psychological adjustment to stress: a meta-analysis. Journal of clinical psychology, 61(4), 461-480. https://doi.org/10.1002/jclp.20049

Bah, S. M., \& Aljoudi, A. S. (2014). Taking a religious perspective to contain Ebola. Lancet (London, England), 384(9947), 951. https://doi.org/10.1016/S0140-6736(14)61344-1

Bhui, K., King, M., Dein, S., \& O'Connor, W. (2008). Ethnicity and religious coping with mental distress. Journal of Mental Health, 17(2), 141-151. https://doi.org/10.1080/09638230701498408

Bonelli, R. M., \& Koenig, H. G. (2013). Mental disorders, religion and spirituality 1990 to 2010: A systematic evidence-based review. Journal of Religion and Health, 52(2), 657-673. https://doi.org/10. 1007/s10943-013-9691-4

Büssing, A., Fischer, J., Ostermann, T., \& Matthiessen, P. F. (2009). Reliance on God's help as a measure of intrinsic religiosity in healthy elderly and patients with chronic diseases. Correlations with healthrelated quality of life? Applied Research in Quality of Life, 4, 77-90. https://doi.org/10.1007/ s11482-009-9068-8

Carey, L. B. (2020). COVID-19, aged care, cancer, medical research and mental health. Journal of Religion and Health, 59(6), 2667-2670. https://doi.org/10.1007/s10943-020-01127-z

Carey, L. B., Swift, C., \& Burton, M. (2020). COVID-19: Multinational perspectives of providing chaplaincy, pastoral, and spiritual care. Health and Social Care Chaplaincy, 8(2), 133142. https://journals.equinoxpub.com/index.php/HSCC/article/view/41973 
Chan, A. O., \& Huak, C. Y. (2004). Psychological impact of the 2003 severe acute respiratory syndrome outbreak on health care workers in a medium size regional general hospital in Singapore. Occupational Medicine, 54(3), 190-196. https://doi.org/10.1093/occmed/kqh027

Cinnirella, M., \& Loewenthal, K. M. (1999). Religious and ethnic group influences on beliefs about mental illness: A qualitative interview study. British Journal of Medical Psychology, 72(4), 505524. https://doi.org/10.1348/000711299160202

Cummings, J. P., \& Pargament, K. I. (2010). Medicine for the spirit: Religious coping in individuals with medical conditions. Religions, 1(1), 28-53. https://doi.org/10.3390/rel1010028

De Roo, A., Ado, B., Rose, B., Guimand, Y., Fonck, K., \& Colebunders, R. (1998). Survey among survivors of the 1995 Ebola epidemic in Kikwit, Democratic Republic of Congo: their feelings and experiences. Tropical Medicine \& International Health, 3(11), 883-885. https://doi.org/10. 1046/j.1365-3156.1998.00322.x

Ellison, C. G., \& Lee, J. (2010). Spiritual struggles and psychological distress: Is there a dark side of religion? Social Indicators Research, 98, 501-517.

Exline, J. J. (2013). Religious and spiritual struggles. In K. I. Pargament, J. J. Exline, \& J. W. Jones (Eds.), APA handbook of psychology, religion, and spirituality (Vol. 1): Context, theory, and research (pp. 459-475). American Psychological Association

Exline, J. J., Pargament, K. I., Grubbs, J. B., \& Yali, A. M. (2014). The religious and spiritual struggles scale: Development and initial validation. Psychology of Religion and Spirituality, 6(3), 208-222. https://doi.org/10.1037/a0036465

Fekih-Romdhane, F., Tounsi, A., Ben Rejeb, R., \& Cheour, M. (2020). Is Religiosity Related to Suicidal Ideation Among Tunisian Muslim Youth After the January 14th Revolution? Community Mental Health Journal, 56(1), 165-173. https://doi.org/10.1007/s10597-019-00447-z

Gearing, R. E., \& Lizardi, D. (2009). Religion and suicide. Journal of Religion and Health, 48(3), 332-341. https://doi.org/10.1007/s10943-008-9181-2

Hart, C. W., \& Koenig, H. G. (2020). Religion and health response to the COVID-19 pandemic. Journal of Religion and Health, 59(3), 2191-2192. https://doi.org/10.1007/s10943-020-01085-6

Hood, R. W., Spilka, B., Hunsberger, B., \& Gorsuch, R. (2003). The psychology of religion: An empirical approach (3rd ed.). Guilford Press.

Ironson, G., \& Kremer, H. (2009). Spiritual transformation, psychological well-being, health, and survival in people with HIV. The International Journal of Psychiatry in Medicine, 39(3), 263-281. https://doi.org/10.2190/PM.39.3.d

Karademas, E. C. (2010). Illness cognitions as a pathway between religiousness and subjective health in chronic cardiac patients. Journal of Health Psychology, 15(2), 239-247. https://doi.org/10. $1177 / 1359105309347585$

Khalaf, D. R., Hlais, S. A. A., Haddad, R. S., Mansour, C. M., Pelissolo, A. J., \& Naja, W. J. (2014). Developing and testing an original Arabic religiosity scale. Middle East Current Psychiatry, 21(2), 127-138. https://doi.org/10.1097/01.XME.0000444753.76812.79

Koenig, H. G., Pargament, K. I., \& Nielsen, J. (1998). Religious coping and health status in medically ill hospitalized older adults. Journal of Nervous and Mental Disease, 186(9), 513-521. https:// doi.org/10.1097/00005053-199809000-00001

Ladd, K. L., \& McIntosh, D. N. (2008). Meaning, god, and prayer: Physical and metaphysical aspects of social support. Mental Health, Religion and Culture, 11(1), 23-38. https://doi.org/10.1080/ 13674670701475053

Lawler-Row, K. A., \& Elliott, J. (2009). The role of religious activity and spirituality in the health and wellbeing of older adults. Journal of Health Psychology, 14(1), 43-52. https://doi.org/10.1177/ 1359105308097944

Lepore, S. J., Silver, R. C., Wortman, C. B., \& Wayment, H. A. (1996). Social constraints, intrusive thoughts and depressive symptoms among bereaved mothers. Journal of Personality and Social Psychology, 70(2), 271-282. https://doi.org/10.1037//0022-3514.70.2.271

Liu, Q., Luo, D., Haase, J. E., Guo, Q., Wang, X. Q., Liu, S., Xia, L., Liu, Z., Yang, J., \& Yang, B. X. (2020). The experiences of health-care providers during the COVID-19 crisis in China: a qualitative study. The Lancet. Global health, 8(6), e790-e798. https://doi.org/10.1016/S2214-109X(20) 30204-7

Lovibond, P. F., \& Lovibond, S. H. (1995). The structure of negative emotional states: Comparison of the depression anxiety stress scales (DASS) with the beck depression and anxiety inventories. Behaviour Research and Therapy, 33(3), 335-343. 
Marshall, K. (2016). Responding to the Ebola epidemic in West Africa: What role does religion play? Georgetown University (Ed.). Washington, DC: Berkley Center for Religion, Peace, and World Affairs http://wvi.org/sites/default/files/Berkley\%20Center\%20Religion\%20and\%20Ebola\% 20Case\%20Study.pdf

Marshall, K., \& Smith, S. (2015). Religion and Ebola: Learning from experience. The Lancet, 386(10005), e24-e25. https://doi.org/10.1016/S0140-6736(15)61082-0

Matua, G. A., \& Wal, D. M. (2015). Living under the constant threat of Ebola: a phenomenological study of survivors and family caregivers during an Ebola outbreak. Journal of Nursing Research, 23(3), 217-224. https://doi.org/10.1097/jnr.0000000000000116

McCauley, M., Minsky, S., \& Viswanath, K. (2013). The H1N1 pandemic: media frames, stigmatization and coping. BMC Public Health, 13, 1116. https://doi.org/10.1186/1471-2458-13-1116

McConnell, K. M., Pargament, K. I., Ellison, C. G., \& Flannelly, K. J. (2006). Examining the links between spiritual struggles and symptoms of psychopathology in a National Sample. Journal of Clinical Psychology, 62(12), 1469-1484. https://doi.org/10.1002/jclp.20325

McIntosh, D. N., Poulin, M. J., Silver, R. C., \& Holman, E. A. (2011). The distinct roles of spirituality and religiosity in physical and mental health after collective trauma: A national longitudinal study of responses to the 9/11 attacks. Journal of Behavioral Medicine, 34(6), 497-507. https://doi.org/10. 1007/s10865-011-9331-y

McIntosh, D. N., Silver, R. C., \& Wortman, C. B. (1993). Religion's role in adjustment to a negative life event: Coping with the loss of a child. Journal of Personality and Social Psychology, 65(4), 812-821. https://doi.org/10.1037//0022-3514.65.4.812

Merhi, R., \& Kazarian, S. S. (2012). Validation of the Arabic translation of the multidimensional scale of perceived social support (Arabic-MSPSS) in a Lebanese community sample. Arab Journal of Psychiatry, 23(2), 159-168.

Mok, E., Chung, B. P., Chung, J. W., \& Wong, T. K. (2005). An exploratory study of nurses suffering from severe acute respiratory syndrome (SARS). International Journal of Nursing Practice, 11(4), 150-160. https://doi.org/10.1111/j.1440-172X.2005.00520.x

Moussa, M. T., Lovibond, P., Laube, R., \& Megahead, H. A. (2017). Psychometric properties of an Arabic version of the depression anxiety stress scales (DASS). Research on Social Work Practice, 27(3), 375-386.

Ozalp, M. (2020). How coronavirus challenges Muslims' faith and changes their lives. The Conversation. Available on URL: https://theconversation.com/how-coronavirus-challenges-muslims-faith-andchanges-their-lives-133925

Pargament, K. I. (1997). The psychology of religion and coping: Theory, research, practice. Guilford.

Pargament, K. I. (2011). Religion and coping: The current state of knowledge. In S. Folkman (Ed.), The Oxford handbook of stress, health, and coping (pp. 269-288). Oxford University Press.

Pargament, K. I., Koenig, H. G., \& Perez, L. M. (2000). The many methods of religious coping: Development and initial validation of the RCOPE. Journal of clinical psychology, 56(4), 519-543. https:// doi.org/10.1002/(sici)1097-4679(200004)56:4\%3c519::aid-jclp6\%3e3.0.co;2-1

Pargament, K. I., Murray-Swank, N. A., Magyar, G. M., \& Ano, G. G. (2005). Spiritual struggle: A phenomenon of interest to psychology and religion. In W. R. Miller \& H. D. Delaney (Eds.), JudeoChristian perspectives on psychology: human nature, motivation, and change, pp. 245-268. American Psychological Association.

Pargament, K. I., Smith, B. W., Koenig, H. G., \& Perez, L. (1998). Patterns of positive and negative religious coping with major life stressors. Journal for the Scientific Study of Religion, 37(4), 710-724. https://doi.org/10.2307/1388152

Park, C., \& Cohen, L. H. (1993). Religious and nonreligious coping with the death of a friend. Cognitive Therapy and Research, 17, 561-577. https://doi.org/10.1007/BF01176079

Post, B. C., \& Wade, N. G. (2009). Religion and spirituality in psychotherapy: A practice-friendly review of research. Journal of Clinical Psychology, 65(2), 131-146. https://doi.org/10.1002/jclp.20563

Puchalski, C., \& Romer, A. L. (2000). Taking a spiritual history allows clinicians to understand patients more fully. Journal of palliative medicine, 3(1), 129-137. https://doi.org/10.1089/jpm.2000.3.129

Qiu, J., Shen, B., Zhao, M., Wang, Z., Xie, B., \& Xu, Y. (2020). A nationwide survey of psychological distress among Chinese people in the COVID-19 epidemic: implications and policy recommendations. General Psychiatry, 33(2), e100213. https://doi.org/10.1136/gpsych-2020-100213

Rabelo, I., Lee, V., Fallah, M. P., Massaquoi, M., Evlampidou, I., Crestani, R., Decroo, T., Van den Bergh, R., \& Severy, N. (2016). Psychological distress among Ebola survivors discharged from an 
Ebola treatment unit in Monrovia, Liberia - a qualitative study. Frontiers in Public Health, 4, 142. https://doi.org/10.3389/fpubh.2016.00142

Riou, J., \& Althaus, C. L. (2020). Pattern of early human-to-human transmission of Wuhan 2019 novel coronavirus (2019-nCoV), December 2019 to January 2020. Euro surveillance : bulletin Europeen sur les maladies transmissibles = European communicable disease bulletin, 25(4), 2000058. https:// doi.org/10.2807/1560-7917.ES.2020.25.4.2000058

Roy, D., Tripathy, S., Kar, S. K., Sharma, N., Verma, S. K., \& Kaushal, V. (2020). Study of knowledge, attitude, anxiety and perceived mental healthcare need in Indian population during COVID-19 pandemic. Asian Journal of Psychiatry, 51, 102083. https://doi.org/10.1016/j.ajp.2020.102083

Schwerdtle, P. M., De Clerck, V., \& Plummer, V. (2017). Experiences of Ebola survivors: causes of distress and sources of resilience. Prehospital and Disaster Medicine, 32(3), 234-239. https://doi.org/ $10.1017 /$ S1049023X17000073

Shreve-Neiger, A. K., \& Edelstein, B. A. (2004). Religion and anxiety: A critical review of the literature. Clinical Psychology Review, 24(4), 379-397. https://doi.org/10.1016/j.cpr.2004.02.003

Sim, L., Chong, P. N., Chan, Y. H., \& Soon, W. S. (2004). Severe acute respiratory syndrome-related psychiatric and posttraumatic morbidities and coping responses in medical staff within a primary health care setting in Singapore. Journal of Clinical Psychiatry, 65(8), 1120-1127. https://doi.org/ 10.4088/jcp.v65n0815

Tisdale, T. C. (2003). Listening and responding to spiritual issues in psychotherapy: An interdisciplinary perspective. Journal of Psychology and Christianity, 22(3), 262-272.

Tzeng, H. M., \& Yin, C. Y. (2006). Learning to respect a patient's spiritual needs concerning an unknown infectious disease. Nursing Ethics, 13(1), 17-28. https://doi.org/10.1191/0969733006ne847oa

U.S. Department of Health and Human Services: H1N1 Flu: A Guide for Community and Faith-Based Organizations. Washington, DC; 2009. http:// www.flu.gov/planning-preparedness/community/ cfboguidance.pdf.

Wang, C., Pan, R., Wan, X., Tan, Y., Xu, L., McIntyre, R. S., Choo, F. N., Tran, B., Ho, R., Sharma, V. K., \& Ho, C. (2020). A longitudinal study on the mental health of general population during the COVID-19 epidemic in China. Brain, Behavior, and Immunity, 87, 40-48. https://doi.org/10.1016/j. bbi.2020.04.028

WHO. (2020). Rolling updates on coronavirus disease (COVID-19). URL https://www.who.int/emerg encies/diseases/novel-coronavirus-2019/events-as-theyhappen (accessed 3.31.20).

Wilt, J. A., Grubbs, J. B., Exline, J. J., \& Pargament, K. I. (2016). Personality, religious and spiritual struggles, and well-being. Psychology of Religion and Spirituality, 8(4), 341-351. https://doi.org/10. $1037 / \mathrm{re} 10000054$

Wu, S.Y. The recall diary of an intern. 4 May, 2004. Retrieved 26 August, 2005, from: http:// www. commonhealth.com.tw/content/056/sars_diary02.asp (in Chinese).

Xiang, Y. T., Yang, Y., Li, W., Zhang, L., Zhang, Q., Cheung, T., \& Ng, C. H. (2020). Timely mental health care for the 2019 novel coronavirus outbreak is urgently needed. The lancet. Psychiatry, 7(3), 228-229. https://doi.org/10.1016/S2215-0366(20)30046-8

Zhang, J., Wu, W., Zhao, X., Zhang, W. (2020). Recommended psychological crisis intervention response to the 2019 novel coronavirus pneumonia outbreak in China: a model of West China Hospital. Precision Clinical Medicine, pbaa006.

Zimet, G. D., Dahlem, N. W., Zimet, S. G., \& Farley, G. K. (1988). The multidimensional scale of perceived social support. Journal of Personality Assessment, 52(1), 30-41.

Publisher's Note Springer Nature remains neutral with regard to jurisdictional claims in published maps and institutional affiliations. 